\title{
Um Estudo de Organização Hospitalar
}

\author{
Humberto Leal Vieira \\ I - CONSIDERAÇÕES GERAIS
}

A Administração Hospitalar no Brasil vem despendendo esforços no sentido de acompanhar o desenvolvimento do país pela adoção de modernas técnicas dè administração. Equipes de médicos, de engenheiros e de arquitetos há muito vêm se dedicando ao aperfeiçoamento de nossos hospitais, quer realizando cursos de administração hospitalar, quer realizando trabalhos de organização.

No presente trabalho visamos tão-sòmente apresentar nossa pequena colaboração ao estudo de administração, registrando nossa experiência na Fundação Hospitalar do Distrito Federal. onde há cêrca de 4 anos exercemos a função de Assessor de Administração Hospitalar. (2)

1. Para uma melhor compreensão da matéria aqui exposta, devemos dizer que encaramos o hospital moderno como uma emprêsa de serviço e por conseguinte a administração hospitalar é passivel de adaptar-se às modernas técnicas de administração empresarial.

Em verdade, no estágio atual da administração, não mais se concebe a clássica estrutura dos antigos hospitais de "santas casas de misericórdias", em que o cliente não é necessàriamente pobre, sem recursos, classificado como indigente. Entendemos que o paciente que demanda a um hospital é um cliente da emprê-

(1) Entre as equipes que se dedicam aos estudos de administração hospitalar podemos citar: Pedroso;

a) Equipe da Escola Paulista de Hospitais, liderada pelo Prof. Odair

b) Equipe de Consultoria Hospitalar, liderada pelo Arquiteto Jarbas Karman;

c) Equipe da PUC, liderada pelo Prof. Genison Amado.

(2) Na Fundação Hospitalar do Distrito Federal (FHDF) trabalhamos nùma equipe de técnicos de Administração e de Médicos que se dedicaram à administração hospitalar. 
sa e como tal deve ser recebido. Assim, distinguimos três cateqorias de clientes:

a) o cliente particular:

b) $u$ cliente segurado do INPS, IPASE ou de outras instituições seguradoras. e

c) o paciente de serviço social.

Os primeiros ao procurar os serviços do hospital se comprometem a pagar o preço dos serviços prestados de seu próprio bôlso. Os segurados de instituições de previdência transferem o ônus da prestação de serviços para essas instituições. Os pacientes de serviço social são aquêles que pagam uma taxa de serviço proporcional a sua situação econômica, completando o Estado, parcial ou integralmente, o valor da prestação dos serviços, quer por subvenção global, quer por indenização de cada caso particular.

É evidente que essa situação é resultado da própria evolução do Estado e na medida que a socialização, ou as medidas de caráter social são tomadas, mais verdadeiras são aquelas situações

Pois bem, essas mudanças requerem também alterações das perspectivas de administração. Enquantó no passado, e a grande maioria dos hospitais brasileiros ainda u são, os hospitais públicos e mesmo particulares tratavam de pacientes sem lhes cobrar um tostão para praticar a caridade ou "distribuir misericórdias", hoje não se pode ter mais essa visão. pois cada vez que assim procede deixa de cumprir sua finalidade, porquanto, os que podem pagar e não o fazem, tiram a vez, a oportunidade e condições de atendimento daqueles verdadeiramente necessitados.

\section{II - INSTITUIÇÕES DE ADMINIS'TRAÇÃO HOSPITALAR}

No Brasil, bàsicamente, são três os tipos de instituições hospitalares: Santas Casas, Hospitais Públicos e Hospitais Particulares, além de Clinicas Especializadas e Casas de Saúde de caráter privado. Tôdas estas instituições, dedicando-se à medicina curativa, deixam aos Postos de Saúde e Campanhas diversas, a tarefa de saúde pública tão importante nos dias de hoje.

As Santas Casas, tradicionalmente conhecidas como Institutus de Misericórdia, são muitas vêzes responsáveis pela asșistência hospitalar, em grande número nos municípios do Brasil. Constituem talvez a mais antiga instituição hospitalar em nosșo meio, mantidas pela comunidade através de donativos e subvenções do Govêrno. Dedicando-se quase que exclusivamente à 
assistência ao indigente, assumiam, as Santas Casas de Misericórdias, grande responsabilidade social em detrimento da eficiência de seus serviços, pela impossibilidade não só de fixar os profissionais médicos a seu serviço em tempo integral, mas, sobretudo, de adquirir aparelhos modernos que permitissem mais rápido tratamento ao doente, como também especialização de seu corpo clinico.

Mais recentemente interveio o Govêrno na assistência médica criando os institutos e êstes os hospitais para seus filiados. Além dêsses hospitais, outros foram criados diretamente pelo Poder Público, para prestação gratuita de serviços médico-hospitalares ou como campo de ensino e pesquisas, junto às Universidades e Faculdades de Medicina. Dois tipos de hospitais públicos surgiram: um em que os serviços prestados eram diretamente pagos através da contribuição do empregado, mensalmente descontados em seu salário, e o outro inteiramente gratuito, como se tôda a sociedade a que servisse fôsse indigente. $O$ resultado dêsse tstado de coisas é que a maior parte da população que trabalha, e que pode econômicamente, é prejudicada em virtude de não desfrutar de uma assistência hospitalar eficiente, pela impossibilidade cada vez mais crescente do Estado de manter em funcionamento ns atuais hospitais, sem se falar na modernização de seus equipamentos ou mesmo de colocar em funcionamento outros já construídos.

$\mathrm{Na}$ impossibilidade de o profissional médico dedicar-se integralmente às instituiçces hospitalares existentes, quer pela baixa remuneração ou mesmo pela proibição fornial de exercer sua clinica particular nessas instituições, partiu para a constituição de sociedades privadas e, conseqüentemente, para a criação de hospitais e casas de saúde particulares.

As conseqüências dessa última solução não são das melhores para os profissionais, para os pacientes e para a sociedade em geral. Os inconvenientes para os médicos se traduzem em aplicação de grande soma de capitais e nos encargos de administrałão, para os quais geralmente não são preparados. Para o paciente, ao lado do bom acolhimento que possam as instituições privadas prestar aos abastados, surge o desinterêsse da prestação de serviços aos menos favorecidos. Além disso, em face da necessidade de grande inversão de capital para aquisição de modernos equipamentos, essas instituições são limitadas em sua ação, quando não põem em risco a vida daqueles que batem à sua porta, levados pelo bom tratamento recebido, sem se preocupar com as limitações dos recursos de seus aparelhos e instrumentos, cujos custos só o Estado pode suportar. E a sociedade? Também sofre as conseqüências dêsse estado de coisas. As rendas e os 
lucros, carreados para os bolsos particulares, bem poderiam ser destinados a compensarem a assistência prestada aos menos favorecidos e mesmo aos comprovadamente indigentes, mediante seleção econômica.

Modernamente já se tenta fazer a medicina integrada, onde, no mesmo hospital, os profissionais se preocupam com a medicina preventiva. O ideal é chegarmos ao ponto de invertermos a situação atual, isto é, dedicar-se o hospital à medicina preventiva c supletivamente à medicina curativa.

Além dessa preocupação, outras nos parecem bastante importantes, quais sejam a de fixar o médico em seu ambiente hospitalar, dividir os custos indiretos de hospitais de uma mesma região e liberar o médico de encargos de administração.

Essas preocupações nortearam nossos trabalhos na Fundação Hospitalar do Distrito Federal, conforme veremos no decorrer desta exposição.

\section{III - EXPERIÊNCIA DE ORGANIZAÇÃo NA F.H.D.F.}

A Fundação Hospitalar do Distrito Federal foi mandada instituir pelo Decreto Federal n $n^{\circ} 48.298$, de 17 de junho de 1960 . Posteriormente foi aprovado seu estatuto, reformulado em 29 de junho de 1964.

Constitui o F.H.D.F. um tipo de emprêsa pública com personalidade juridica de Direito Privado, entidade descentralizada da Prefeitura do Distrito Federal e vinculada à Secretaria de Saúde.

De acôrdo com o plano inicial da assistência médica em Brasilia, a Fundação Hospitalar foi incumbida de prestar, através de seus hospitais, assistência médica aos habitantes da Capital da República. Pelo plano original deveria existir um hospital de base - Hospital Geral - e vários hospitais distritais espalhados no Plano Pilôto e Cidades-Satélites.

Atualmente, enquanto não é construido o hospital de base, - 10 Hospital Distrital de Brasilia vem funcionando como tal e a medicina preventiva (saúde pública) a cargo da Secretaria de Saúde, passou recentemente para a responsabilidade da Fundação, tornando seus hospitais em unidades integradas de saúde. Essas alterações vieram a condicionar uma nova estrutura para a Rêde Hospitalar.

Até 1964 havia um único hospital de grande porte - o 1 \% Hospital Distrital de Brasilia (1\% HDB) -..- projetado para 270 
leitos e ampliado para 500 leitos. Além dêsse hospital existiam construídos em barracões de madeira:

a) Hospital São Vicente de Paulo, em Taguatinga;

b) Hospital Rural do Gama;

c) Hospital de Isolamento para Tubercylosos;

d) Hospital Rural de Sobradinho;

e) Pôsto Médico de Brazlândia.

Essas unidades funcionavam isoladamente sob um pseudo contrôle da Fundação Hospitalar que possuia, por instrumento de organização, apenas um estatuto. As unidades hospitalares não possuiam sequer um regimento. $\mathrm{O}$ mais importante dos hospitais, o 1 HDB, possuia um Regulamento do Corpo Médico que desçonhecia totalmente as atividades de administração. A própria Fundação carecia de um regimento que fixasse a compe. tência de seus vários órgãos.

Talvez por êsse aspecto e por haver um único hospital em pleno funcionamento; a Fundação Hospitalar se confundia com - 1ः HDB, decorrendo dai vários vícios de administração, resultantes dêsse desequilibrio que até hoje luta a FHDF para corrigir.

Era essa a situação da FHDF encontrada pela equipe do DASP, liderada pelo Dr. Propício Caldas Filho, convidado a reorganizar e a assumir postos chaves na administração.

Inicialmente tivemos que levantar a estrutura informal existente, bem como o que se vinha fazendo em cada uma das salas e que trabalhava o pessoal na Administração Central e no $1^{\circ} \mathrm{HDB}$. Posteriormente examinamos o plano hospitalar do Distrito $\mathrm{Fe}$ deral, a fim de projetarmos uma estrutura para a administração central e a correspondente estrutura para cada um dos hospitais da Rêde.

O que havia de experiência anterior em matéria de administraçío hospitalar, pròpriamente dita, pouca coisa se aplicaria ao nosso caso de organização, uma vez que nossa experiência de Fundação não se confundia com a estrutura clássica de hospitais então existentes. Tivemos de buscar nos conhecimentos de organização empresarial as bases para estruturação da Fundação, sem contudo nos descuidarmos das peculiaridades do tipo de emprêsa.

Alguns principios presidiram nosso trabalho:

a) A estrutura inicial deveria suportar as atividades então existentes, sem prejuizo da possível expansão da Rêde Hospitalar; 
b) estruturar de tal meio as atividades médicas que mantivessem, tanto quanto possivel, êsse profissional no ambiente hospitalar;

c) liberar os médicos dos encargos de administração;

d) os custos da administração central seriam divididos com os hospitais da Rêde; integrada;

e) criar condições para a execução dos serviços de medicina

f) possibilitar a pesquisa e a especialização de profissionais médicos e para-médicos, não importando em que hospital da Rêde exerçam sua profissão.

Assim, concebemos a Fundação como um grande hospital, em que o seu Diretor-Executivo é o gerente - um diretor de emprêsa de serviço - onde a situação financeira do estabelecimento depende de sua ação.

Levantados os dados iniciais, estruturamos a Fundação em base departamental com departamentos verticais para as atividades-fins e uma departamentalização horizontal para as atividadesmeio.

Recentemente submetemos também as atividades-fins a uma departamentalização horizontal, fazendo passar na estrutura vertical de cada hospital, à coordenação de cada especialidade médica, o que se tornou a célula dos departamentos de especialidades quando vier a funcionar o hospital de base da Rêde.

Inicialmente, dois niveis de administração foram delimitados:

a) Uma Administração Central; e

b) as Unidades Hospitalares.

Na Administração Central, sob a direção de um Diretor Executivo, foram criados 3 grandes departamentos:

a) Departamento de Administração;

b) Departamento Econômico e Financeiro;

c) Departamento Hospitalar.

Os dois primeiros departamentos foram desde o início estruturados à base de sistemas. O Departamento Hospitalar só recentemente, com o crescimento da Rêde, é que se estruturou em sistemas, introduzindo as coordenações de especialidades médicas e a coordenação de atividades técnicas, a exemplo do que já vinha funcionando com as atividades-meio através das diversas divisões: 
Nessa ordem de idéias temos os seguintes sistemas:

A - Sistemas de atividades-meio

1 - No Departamento de Administração:

a) Sistema de Pessoal;

b) Sistema de Material;

c) Sistema de Comunicações e Arquivo;

d) Sistema de Manutenção e Transportes;

e) Sistema de Obras e Patrimônio;

f) Sistema de Serviços Gerais.

2 - No Departamento Econômico e Financeiro:

a) Sistema de Contabilidade;

b) Sistema de Seleção Econômica;

c) Sistema de Tesouraria.

B - Sistemas de atividades técnicas

1 - No Departamento Hospitalar:

a) Coordenação de Enfermagem;

b) Coordenação de Nutrição e Dietética;

c) Coordenação de Farmácia;

d) Coordenação de Bibliotecas;

e) Coordenação de Arquivo Médico e Estatística.

C - Sistema de atividades-fins

1 - No Departamento Hospitalar:

a) Coordenação de Especialidades Médicas

- Coordenação de Cirurgia

- Coordenação de Ortopedia e Fisioterapia

- Coordenação de Pediatria

- Coordenação de Ginecologia e Obstetrícia

- Coordenação de Cardiologia, etc.

As atividades-meio constam da estrutura de todos os hospitais da Rêde, assim como as atividades técnicas e grande parte das atividades-fins, no caso, as atividades de especialidades médicas. A coordenação dessas atividades nos diversos hospitais é assegurada através de um órgão central que, no caso dos Departamentos de Administração e Econômico e Financeiro, são chamados de "Divisão" e no Departamento Hospitalar são denominados de "Coordenação".

Convencionou-se chamar de "Divisão" ao órgão central do sistema que fôsse' ao mesmo tempo órgão de execução, relativamente às atividades desempenhadas na Administração Central e de coordenação em relação aos respectivos serviços a estrutura das Unidades Hospitalares. Enquanto a "Coordenação" não detém funções executivas e sim de coordenação dos serviços, ou especialidades das Unidades Hospitalares, além de exercer as funções de assessoramento à alta administração em assuntos de 
aquisição, especificação, distribuição de material da especialidade, de seleção, distribuição e treinamento de pessoal da especialidade, etc.

Cada sistema é constituido por um órgão central e órgãos periféricos. O órgão central é representado, como vimos, pelas "Divisões" e pelas "Coordenações" e os órgãos periféricos pelos "Serviços" e "Seções" nos hospitais.

Assim, o "Sistema de Pessoal" é constituido pelos:

Órgão Central: Divisão do Pessoal (do Dep. de Adm.)

Órgão Periférico: Seção de Pessoal (das Div. de Adm. dos Hosp.).

O "Sistema de Nutrição e Dietética" é constituido pelos:

Órgão Central: Coordenação de Nutrição e Dietética do Dep. Hospitalar.

Órgão Periférico: Serviço de Nutrição e Dietética da Divisão Técnica dos Hospitais.

O "Sistema de Pediatria" é constituido pelos: pitalar.

Órgão Central: Coordenação de Pediatria do Dep. Hos-

Órgão Periférico: Serviços de Pediatria das Divisões Médicas dos Hospitais.

A estrutura das unidades hospitalares encontra-se, nio momento, em estudos com o objetivo de ajustá-la à recente estruturação da Administração Central no que diz respeito às "Coordenações" do Departamento Hospitalar. (3)

$\mathrm{Na}$ fase atual dos estudos sugerimos a seguinte organização básica para a unidade hospitalar:

\section{Diretor}

1. Divisão de Administração

2. Serviço Econômico e Financeiro

3. Divisão Técnica

4. Divisão de Enfermagem

5. Divisão Médica

Essas "Divisões", com seus Serviços e Seções, se subordinam administrativamente ao Diretor do Hospital e tècnicamente às Coordenações ou às Divisões de Administração Central. Com isso liberamos o diretor do hospital de uma série de tarefas adminis-

(3) As "Coordenações" do Departamento Hospitalar foram criadas em 11 de junho de 1968 . 
trativas de ordem técnica e também da orientação precisa dos trabalhos de especialidades médicas. Dentro dessa estrutura, ao diretor do hospital incumbe, bàsicamente, coordenar os órgãos setoriais dos diversos sistemas e manter a disciplina e a ordem em seu hospital.

A estrutura hospitalar acima mencionada, conforme dissemos, ainda se encontra em estudos embora seja pacifica sua aceitação, com exceção da Divisão de Enfermagem que alguns reagem a sua criação.

Os principais opositores da Divisão de Enfermagem sugerem a criação de um Serviço de Enfermagem na Divisão Técnica, juntamente com os Serviços ali previstos: Serviço de Arquivo Médico e Estatística, Serviço de Nutrição e Dietética e a Farmácia Hospitalar.

Alguns médicos receiam que a criação de uma Divisão de Enfermagem, no mesmo nivel de uma Divisão Médica, venha causar problemas de relações internas de funcionamento $e$, por conseguinte, a Enfermagem deve estar subordinada à Divisão Técnica, em nivel de Serviço.

A nosso ver, êsse argumento não resiste a uma análise de organização em que pese a opinião de ilustres médicos que se dedicam à Administração Hospitalar, senão vejamos:

a) O pessoal de enfermagem representa 55 a $60 \%$ do pessoal em exercicio no hospital. Se criamos uma Divisão Técnica com $10 \%$ e um Divisão Médica com $15 \%$ de pessoal, como "es condermos" $60 \%$ do pessoal de enfermagem na Divisão Técnica? Forçosamente cairiamos no desequilibrio de estrutura e o Chefe da Divisão Técnica teria sua atividade voltada aos problemas de enfermagem, em detrimento dos demais serviços da Divisão;

b) a mecânica dos serviços de enfermagem não se confundem nem se assemelham com os demais serviços da Divisão Técnica;

c) uma organização hospitalar que possui cêrca de 7 leitos para uma enfermeira, em seu principal hospital com 520 leitos, não vemos razões para não dotá-lo de uma Divisão de Enfermagem;

d) não vemos razões para temer relações internas de funcionamento quando a prestação da assistência ao paciente deve ser realizada em equipe onde participa, não só o médico e a enfermeira, mas também a nutricionista, o farmacêutico e porque não dizer também indiretamente os órgãos de administração-meio, integrantes de uma Divisão - a Divisão de Administração. 
Confiamos, entretanto, que o tradicionalismo na administração hospitalar cederá lugar às modernas técnicas de organização, que se acham acima das divergências entre médicos e enfermeiros.

IV - A ASSISTÊNCIA MÉDICA PRESTADA PELA F.H.D.F.

A Fundação Hospitalár, que em 1964 contava apenas um hospital totalmente construído, além de 4 outros em barracões improvisados, conta hoje com as seguintes unidades hospitalares:

a) 1\% Hospital Distrital de Brasilia (1\% HDB) -520 leitos

b) Hospital Distrital L2-Sul (HDL2-SUL) - 120 leitos

c) Hospital Distrital do Gama (HDG) - 250 leitos (4) d) Hospital Distrital de Sobradinho (HDS) - 250 leitos (5)

e) Hospital São Vicente de Paulo (HSVP) - 60 leitos (6)

Além dessas unidades hospitalares já se encontram programadas para funcionar nesses próximos 2 anos:

a) Hospital Distrital de Taguatinga - 500 leitos

b) Hospital de Brazlândia - 100 leitos (7)

c) Hospital Psiquiátrico - 300 leitos.

Recentemente, em junho do ano passado, foram transferidos, da Secretaria de Saúde para a Fundação, os Postos de Saúde: (8).

a) Unidade Isolada de Saúde W-3;

b) Unidade Isolada de Saúde do Núcleo Bandeirante;

c) Unidade Isolada de Saúde de Planaltina.

Integrará brevemente a Fundação Hospitalar o Centro de Orientação Médico Psico-Pedagógico, instituição mantida por por convênio entre as Fundações: de Serviço Social, Educacional é Hospitalar.

(4) O Hospital Distrital do Gama será acrescido de mais 60 leitos para tuberculosos, que funcionarão em um Anexo e para onde será transferido o atual Hospital de Tamboril.

(5) O Hospital Distrital de Sobradinho (Unidade Integrada de Saúde de Sobradinho - UISS) funciona como hospital-escola mantido em convênio com a Universidade de Brasilia.

(6) O Hospital São Vicente de Paulo, em Taguatinga, contará em abril com uma ampliação para os serviços de Pronto-Socorro até que seja construido seu nôvo hospital de 500 leitos.

(7) O Hospital de Brazlândia, cuja concorrência já foi realizada, contará com 100 leitos inicialmente, com possibilidade de ampliação de mais 300. Atualmente ali existe funcionando um Pôsto Médico.

(8) Os Postos de Saúde ao passarem para a Fundação foram denominados de Unidade Isolada de Saúde. A denominação de "Isolada" está em oposição à Unidade «Integrada», considerando-se como tal os hospitais, embora, explique-se que a Unidade "Isolada" também faça medicina assistencial (ambulatório) e não sòmente saúde pública. No momento que é construído um hospital a Unidade Isolada deixa de existir para se integrar na estrutura do hospital e passar a ser Unidade Integrada. 
É oportuno ressaltar que nos hospitais da Rêde se pratica a medicina integrada, e onde não há hospital, há a unidade isolada de saúde, que além das atividades de saúde pública exerce a medicina assistencial.

Em resumo, podemos afirmar que a Fundação Hospitalar do Distrito Federal constitui uma nova experiência de administração hospitalar, com resultados provados pela prática e que, adaptados às peculiaridades de cada Estado, poderá ser experimentada em qualquer parte do nosso território.

Quando a comunidade de nossos Estados participar do custeio da prestação dos serviços médicos hospitalares, como acontece em Brasilia (9), estamos certos que haverá dinheiro para manter nossos hospitais públicos e mais que isso, de abrirmos os inúmeros hospitais que, embora construidos e já aparelhados, mantêm-se por 5,10 ou mais anos, sem receber sequer um paciente.

É necessário, portanto, que a comunidade não espere pelos favores dos Podêres Públicos, mas que vá ao seu encontro para juntos conjugar esforços no sentido de usufruir de uma assistência médica capaz de lhe proporcionar a saúde de que tanto necessita nosso pqvo.

(9) Em Brasilia cêrca de $80 \%$ do custeio da prestação de assistência médica nos hospitais da Fundação é coberto pela arrecadação e essa taxa tende a subir na medida que é implantada em tôda a Rêde a seleção econômica, a cargo do Departamento Econômico e Financeiro.

HuMBerto LEAL VIEIRA - Bacharel em Administração pela Escola Brasileira de Administração Pública da F.G.V. - 1962; Pós-Graduação na Ecole Nationale d'Administration Publique - Paris - 1964/65; Técnico de Administração do DASP e Assessor do Secretário de Saúde e do Diretor Executivo da Fundação Hospitalar do Distrito Federal. 